\title{
RESENHA DE O FUTURO, DE MACHADO DE ASSIS (ORGANIZAÇÃO, INTRODUÇÃO E NOTAS DE RODRIGO CAMARGO DE GODOI)
}

\author{
REVIEW OF O FUTURO, BY MACHADO DE ASSIS (EDITING, INTRODUCTION \\ AND NOTES BY RODRIGO CAMARGO DE GODOI)
}

ASSIS, Machado de. O Futuro. Organização, introdução e notas de Rodrigo Camargo de Godoi. Campinas, SP: Ed. da Unicamp, 2014. 168 p.

\section{ALEX SANDER LUIZ CAMPOS}

Instituto Federal do Norte de Minas Gerais

Almenara, Minas Gerais, Brasil

\begin{abstract}
e é verdade, como disse Antonio Candido, que uma das qualidades da crônica está no fato de não ser um "gênero maior" - condição que a aproximaria mais do leitor, que faria dela texto capaz de mostrar a beleza insuspeitada do cotidiano -, ${ }^{1}$ é também verdade que a consequente "superioridade" de outros gêneros fez com que a crônica, por muito tempo, fosse vista como porção periférica da obra de um escritor. Como texto menor, não deveria possuir os mesmos privilégios das grandes criações, como o romance. Quando falamos em privilégios, não nos referimos somente à prioridade de leitura ou estudo, mas à própria edição do texto, à sua divulgação para um público maior. Na literatura brasileira, o caso de Machado de Assis parece ser exemplar do cuidado editorial (ou da falta dele) com os textos considerados menos ou não relevantes: enquanto um romance como Dom Casmurro já mereceu duas edições críticas, ${ }^{2}$ várias das séries de crônicas publicadas por Machado na imprensa fluminense permaneceram, por décadas, com acesso dificultado e, quando muito, com a única opção de edições problemáticas ou incompletas.
\end{abstract}

\footnotetext{
${ }^{1}$ CANDIDO, A vida ao rés-do-chão, p. 14.

${ }^{2}$ Cf. ASSIS, Dom Casmurro (edição realizada pela Comissão Machado de Assis); ASSIS, O romance Dom Casmurro de Machado de Assis. 
Felizmente, nem todos os estudiosos de Machado viram ou veem a crônica como texto de interesse exclusivo do público do Oitocentos. No que toca à edição das crônicas em livro, pelo menos dois nomes devem ser lembrados: Raimundo Magalhães Júnior e John Gledson. Em 1956, Magalhães Júnior publicava a primeira edição da série "Bons dias!" (a que acrescentou outros textos): Diálogos e reflexões de um relojoeiro. Além de apresentar as crônicas, o pesquisador escreveu o primeiro estudo da série $\mathrm{e}^{3} \mathrm{e}$ a anotou, facilitando, em certa medida, a vida do leitor. Ao pesquisador inglês Gledson devemos não apenas o acesso a boas edições das crônicas como também uma notável reivindicação da importância da cuidadosa edição desses textos. ${ }^{4}$ Há dois anos (2013), como apêndice para uma antologia que fez das crônicas machadianas, Gledson escreveu texto em que avalia criticamente as várias edições de que hoje já dispomos das crônicas de Machado, apontando qualidades e deficiências. ${ }^{5}$ Sobre uma série em particular, no entanto, intitulada apenas de "Crônica" e publicada em efêmero periódico (O Futuro), a avaliação de Gledson se resumiu ao seguinte: "até agora, não há edição completa e anotada desta série". 6

Recente lançamento da Editora da Unicamp vem preencher essa lacuna. Com organização, introdução e notas de Rodrigo Camargo de Godoi, O Futuro - livro que reúne, pela primeira vez em um só volume dedicado a elas, as dezesseis crônicas de Machado publicadas entre 1862 e 1863 na revista luso-brasileira $O$ Futuro: Periódico Literário - é um trabalho pelo qual esperávamos desde 2008, quando a Editora da Unicamp divulgou o projeto da Coleção Crônicas de Machado de Assis, que tem por objetivo reunir em até quinze volumes a totalidade das crônicas machadianas.?

O livro tem vários méritos; a simples divulgação de textos machadianos pouco conhecidos seria motivo suficiente para justificar a publicação. A edição, entretanto, vai além: ao tomar como base para o estabelecimento do texto a própria revista $O$ Futuro (e não edições em livros anteriores, como as preparadas pela Jackson ou pela Nova Aguilar), permite que o leitor disponha de um texto bem mais confiável. Segundo o editor, Rodrigo Camargo de Godoi, o volume foi preparado com base em pesquisas realizadas no Arquivo Edgar Leuenroth, da Unicamp, na Biblioteca

\footnotetext{
${ }^{3}$ MAGALHÃES JÚNIOR, Prefácio. In: ASSIS, Diálogos e reflexões de um relojoeiro, p. 1-18.

${ }^{4}$ Cf. GLEDSON, Nota às notas. In: ASSIS, A Semana, p. 41-42.

${ }^{5}$ GLEDSON, A história das edições das crônicas machadianas. In: ASSIS, Crônicas escolhidas, p. 313319.

${ }^{6}$ Idem, p. 317.

${ }^{7}$ Cf. <http://www.unicamp.br/unicamp/unicamp_hoje/ju/agosto2008/ju406_pag02-a.php>.
} 
Brasiliana Guita e José Mindlin, na USP, e na Fundação Casa de Rui Barbosa. Seria interessante, a nosso ver, que também fosse consultada, para o estabelecimento do texto, a segunda edição da revista, publicada em 1867 no Rio de Janeiro pelo português A. A. da Cruz Coutinho e disponível atualmente no acervo da Faculdade de Letras da Universidade do Porto nada, entretanto, que comprometa o trabalho realizado.

Deve-se destacar nessa edição a qualidade da Introdução e das notas. Godoi é mestre em Teoria e História Literária e doutorando em História Social pela Unicamp, instituição em que defendeu o estudo Entre comédias e contos: A formação do ficcionista Machado de Assis. É visível, em vários momentos, o bom conhecimento que o pesquisador tem da imprensa oitocentista brasileira, o que nos ajuda a ler melhor várias das passagens das crônicas. As fontes de que se utilizou para esclarecer referências presentes nas crônicas a pessoas, livros, instituições, entre outros, são bastante confiáveis e estão devidamente identificadas. Os índices ao final do volume são um valioso instrumento de trabalho, pois permitem ao leitor identificar facilmente referências a assuntos e nomes nas crônicas.

Com o intuito de contribuir para o trabalho difícil de edição das crônicas é que apontamos (pequenos) problemas no texto preparado por Godoi e incoerências em relação aos critérios de edição. ${ }^{8}$ A pontuação machadiana foi modificada diversas vezes, o que, em si, não é um problema, uma vez que a pontuação utilizada hoje difere em muitos aspectos da utilizada no século XIX (por exemplo: hoje não separamos mais, com vírgula, sujeito e predicado), e a edição em livro das crônicas objetiva justamente apresentar o texto para o leitor atual. Entretanto, na "Nota à edição", somos informados de que a pontuação original machadiana fora mantida. Como o critério da edição foi a atualização ortográfica, os nomes dos meses deveriam vir todos com inicial minúscula, certas palavras deveriam vir sem o apóstrofo (como "d'aqui" e "d'entre") e a palavra "de certo" (grafia oitocentista), com o sentido de "certamente", deveria estar grafada sem o espaço entre os elementos que a compõem. Alguns nomes próprios foram atualizados ("Bocaiuva", p. 95, em vez de "Bocayuva", p. 372 d'OF; “Artur”, p. 160, sem o "th"), enquanto outros não (Raphael, p. 159, permanece com o "ph"; o sobrenome de Faustino Xavier de Novais permanece "Novaes" - v. p. 138). Encontramos vários casos de (mínima) discrepância entre o texto original e o texto editado em livro, como "amostra" (p. 39) em vez de "amostras" (p. 38

\footnotetext{
8 Para o cotejo da edição em livro com a revista $O$ Futuro $(=O F)$, recorremos aos exemplares digitalizados pela Brasiliana da USP e disponíveis em $<$ http://www.brasiliana.usp.br/bbd/handle/1918/633>.
} 
d'OF)", "acaba" (p. 49) em vez de "acabou" (p. 202 d'OF), "podemos crer noutra" (p. 51) em vez de "poderemos crer outra" (p. 203 d'OF), "consciência" (p. 58) em vez de "consistência" (na revista está "consistencia" - p. 235 d'OF), “dia 17" (p. 65) em vez de "dia 27" (p. 267 d'OF), “depende” (p. 74) em vez de "dependa" (p. 306 d'OF); "brasileiro" (p. 94) em vez de "brasileiros" (p. 372 d'OF); "fazer" (p. 120) em vez de "fazer um" (p. 466 d'OF); "lhe" (p. 121) em vez de "lha" ("lh'a" na p. 467 d'OF), "certo que" (p. 133) em vez de "certo de que" (p. 531 d'OF), "regeneração. Fora" (p. 137) em vez de "regeneração. [§] Fora" ("Fóra" na p. 563 d'OF), "se refere" (p. 143) em vez de "refere-se" (p. 594 d'OF), "Zaluar" (p. 150) em vez de "A. E. Zaluar" (p. 627 d'OF), "devem caber muitos louvores" (p. 150) em vez de "muitos louvores devem caber" (p. 627 d'OF), entre vários outros casos, todos talvez insignificantes, mas que poderiam ser corrigidos em uma futura edição.

Que venham os próximos volumes da coleção de crônicas machadianas da Editora da Unicamp. Com certeza, novos estudos de Machado de Assis serão impulsionados por esse trabalho tão necessário de edição e anotação das crônicas.

\section{Referências}

ASSIS, Machado de. Dom Casmurro. 2. ed. Rio de Janeiro: Civilização Brasileira, 1977. $267 \mathrm{p}$.

O romance Dom Casmurro de Machado de Assis: edição crítica e comentada por Maximiano de Carvalho e Silva. Niterói: Ed. da UFF, 2014. 480 p.

CANDIDO, Antonio. A vida ao rés-do-chão. In:__ et al. A crônica: o gênero, sua fixação e suas transformações no Brasil. Campinas, SP: Ed. da Unicamp; Rio de Janeiro: Fundação Casa de Rui Barbosa, 1992, p. 13-22.

GLEDSON, John. A história das edições das crônicas machadianas. In: ASSIS, Machado de. Crônicas escolhidas. Organização, introdução e notas de John Gledson. São Paulo: Penguin Classics Companhia das Letras, 2013, p. 313-319.

. Nota às notas. In: ASSIS, Machado de. A Semana: crônicas (1892-1893). São Paulo: Hucitec, 1996, p. 41-42.

MAGALHÃES JÚNIOR, Raimundo. Prefácio. In: ASSIS, Machado de. Diálogos e reflexões de um relojoeiro. Organização, prefácio e notas de R. Magalhães Júnior. Rio de Janeiro: Civilização Brasileira, 1956, p. 1-18.

${ }^{9}$ Como a numeração da revista é contínua, não especificamos o volume. 
ALEX SANDER LUIZ CAMPOS é mestre (2013) e doutorando em Estudos Literários pela Universidade Federal de Minas Gerais e licenciado em Letras pela Universidade Estadual de Montes Claros (2010). É professor da área de língua portuguesa do Instituto Federal do Norte de Minas Gerais. Publicou, entre outros, Machado de Assis contra a concepção de sujeito solar. implicações na crônica (NEA, 2013) e capítulo no livro Arquivos femininos: literatura, valores, sentidos (Org. de Constância Lima Duarte et al., Mulheres, 2014). E-mail: alex.campos@ifnmg.edu.br.

Recebido: 09.03.2015

Aprovado: 27.04.2015 